\title{
Techno-Financial Analysis of Energy Access through Hybrid System with Solar PV under the Various Rural Community Models for State of Uttarakhand, India
}

\author{
Ashish Verma1, Saurabh Biswas², Syed Yasir Ahmad ${ }^{3}$ \\ ${ }^{1}$ Department of Energy System Engineering, University of Petroleum and Energy Studies, Dehradun, India \\ ${ }^{2}$ Department of Electrical Power and Energy, University of Petroleum and Energy Studies, Dehradun, India \\ ${ }^{3}$ The Energy and Resource Institute, New Delhi, India \\ Email: ashish.verma@stu.upes.ac.in, sbiswas@ddn.upes.ac.in, yasir.ahmad207@gmail.com
}

Received 20 November 2014; accepted 21 April 2015; published 30 April 2015

Copyright (C) 2015 by authors and Scientific Research Publishing Inc.

This work is licensed under the Creative Commons Attribution International License (CC BY). http://creativecommons.org/licenses/by/4.0/

\section{Open Access}

\section{Abstract}

Uttarakhand state comes under special category state where approximately $69.45 \%$ population lived in rural area under the population density with varied range of 37 to 607 persons per sq.km. Although Uttarakhand is having per capita consumption of $1112.29 \mathrm{kWh}$ which is higher than national average per capita consumption of $779 \mathrm{kWh}$ as till date, but remote communities, villages are not able to access clean, cheep and good quality of energy due to uneven terrain, lack of proper transmission \& distribution lines [1]. 100\% villages are electrified under the RGGVY scheme as per the Ministry of Power Government of India, but due to poor loading of transformer, lack of grid infrastructure and natural calamities, remote house owners are not able to get good quality of power thus affect the livelihood and source of income generation in various means [2]. As Uttarakhand state having future plans to be make state energy sufficient and energy access to all by year 2016-2017, so major ground level initiative have been taken by Government of Uttarakhand. The government of Uttarakhand has incorporated innovative business model to provide good quality of power with non-conventional energy source. Under the initiative invlovement of local people and village level, panchayats have ownership and responsibility to operate these clean energy business model to improve livelihood in remote hilly places of Uttarakhand. Under this analysis, five different type of community models are categorized as Community 1, Community 2, Community 3, Standalone $1 \&$ Standalone 2 for rural \&remote communities based on number of unclustered households with the distance covered between 200 $\mathrm{m}$ to $20 \mathrm{~km}$, and electrical loads i.e. lighting, fan, mobile chargers, television along with time of day energy consumption patterns. These community models are for remote hilly location where grid integration and distribution lines are not feasible to built due to hilly terrain, low soil strength and 
huge expenses for expanding power cables for supplying good quality power. The preliminary studies and simulations has been done in HOMER tool by considering the various composite source of power, i.e. Solar PV with battery bank, Solar PV with battery Bank \& Generator, and Solar $P V$ along with DG. These three hybrid source of power generation with Solar PV as base source under five different community models, the techno-commercial feasibility has been analyzed in terms of load sharing proposition with Solar PV and battery, DG, Energy production through PV, load consumption per year, Excess and unmet energy monitoring, battery sizing to meet the load during nights, DG operation when the solar energy not available due to weather condition and non availability of sunshine in night. Financial feasibility has been examined in terms of levelized cost of energy, cost summary and 0\&M cost per year of three integrated sources of energy generation with Solar PV under each community model. Solar PV power plant, which is the best renewable source of energy to cater energy access issue in remote hilly places. The Uttarakhand receives good amout of daily average radiation level of $5.14-5.50 \mathrm{kWh} / \mathrm{m}^{2} /$ day. Financial feasible community models for different hilly region based on their energy consumption need to be implemented with the help of local community by providing ownership to local people, panchayat, for it not only caters energy access issue but also provides clean, cheep, uninterruptable energy and improves livelihood standard to locals by engaging them into operation maintenance and tariff or rent collection. The study shows that Solar PV power plant with battery bank is the optimal solution considering life cycle cost of hybrid system. It is feasible due to low operation and maintenance cost, price declination of battery and Solar PV module, battery prices at time of replacement.

\section{Keywords}

Distributed Community Models, HOMER, Hybrid Energy Solution, Solar PV, Hilly Region

\section{Introduction}

Remote and rural communities of developing countries are having lack of essential access to wide range of services, i.e. road, health, energy, education, clean water and information [1]. With the population of more than 1.2 billion, India stands in 136 position in human development index [2] among 187 countries, showing low level of development in terms of life expectance, literacy, education, living standard and quality of life. So how access to energy is having direct or indirect impact on these development indexes. Energy access is all about making accessible to the common man electricity or other services in form of electricity. Referring to the living condition based on geographical diversification in India, lack of energy access is on the top of the all issues. Eliminating the energy poverty among rural and remote communities in India required decentralized solution, i.e. energy infrastructure so that energy development can reach among the billion of people [3]. Centralized energy solution and business models are not enough to cater issues of good quality and supply of energy in rural remote places in hilly regions due to lack of adequate grid infrastructure, difficult terrain and some environmental issues [4]. Centralized energy business model are having these few issues:

- Expansion of grid infrastructure in remote place specially in hilly region;

- Poor quality of power due to lack of nearby substation and distribution network, i.e. AT\&C losses;

- Issue of system reliability;

- Integration of renewable;

- Energy storage in large and long term.

"Power to All by 2012" was the most promising aim of Government of India to provide grid quality energy to all people who were living in India [5]. The fact is that still 400 million of people of India are not able to access energy which can improve their life style, earning and raise their socio-economic status. Almost $60 \%$ of country population is living in rural region, where some of them are getting cheap and good quality power, hilly regions are the worst. Distributed generation of energy through hybrid source is integrated with abundantly available solar energy. And Solar PV is the best solution to energize the rural and remote living communities. Uttarakhand is such a place where the geographical landscape is diversified in such a way that $45.80 \%$ land is covered with forest where it distributed among 13 districts [6]. This paper aims to prepare techno-financial models for providing cheap, clean, uninterruptable and employable energy solution to remote hilly places. 


\section{Research Methodology}

The objective of the study was to compare the various power source options to integrate with Solar PV could provide cheap, reliable and carbon emission free energy in remote places.

The reason for choosing Uttarakhand as part of study is that it's hilly state where population lives in distributed way and it comes under solar insolation range of $5.14-5.50 \mathrm{kWh} / \mathrm{m}^{2} /$ day which having maximum solar insolation than other hilly state i.e. Jammu \& Kashmir, Himanchal Pradesh and north eastern states [7]. In most of the rural communities, villagers are using kerosene oil for cooking and lighting, DG sets to run appliances during special occasions and Solar PV module to be self energy sufficient. The energy consumption pattern of individual household and cluster of house is almost the same due to following the same pattern of daily work in rural place. HOMER geospatial tool developed by NREL is used for both technical and financial analysis which gives a brief landscape of techno-commercial aspect of hybrid energy generation under various models. Under the technical analysis, these five community models cover up:

1) Daily and seasonal load profile;

2) Energy consumption per year;

3) Energy production from Solar PV, DG and battery;

4) Excess generation, unmet load and capacity shortage;

5) Average load, peak load and load factor of community model based on energy consumption profile.

Financial viability analysis covers up levelized cost of energy (LCOE), system cost, O\&M cost per year, and based on these outcomes best hybrid option would be selected for rural energy access. The purpose of this paper is to analyze the techno-financial viability of energy hybrid model for power generation in India through HOMER geospatial tool developed by NREL [8].

The cost of module, battery, Diesel-Generator has been taken with reference of India and we converted the INR to Dollar at the rate of 60 .

\section{Centralized Model of Energy Generation \& Distribution-Issues \& Options}

Modern energy services allow people to cook their food, heat their homes, read in the evening. Only with the access to the sustainable energy, people can eliminate their energy poverty. Although centralized model generates huge amount of power generation in cost effective way, due to issues i.e geographical variability, uneven terrain, long time span for establishing grid infrastructure to send generated power from one corner to place of need, huge financial investment, high T\&D losses and reliability of energy availability. The researcher and business owner saw the opportunity to curtail these issues by opting decentralized energy generation model nearby the service area. Decentralized model has their own characteristics and answers to issues related with centralized model:

- Power generation nearby the service area, i.e. reduce T\&D losses;

- Better monitoring and control of power generation;

- Reduce power transmission and distribution complexity;

- Deployment of renewable energy technology for distributed generation;

- Local employment generation;

- Reduce construction time span for bulk power generation;

- Mitigated individual energy demand and supply gap;

- Best option for rural electrification;

- Easy tariff collection mechanism;

- Empowerment of local bodies, i.e. Panchayat, Gram Sabha through ownership;

- Innovative financing mechanism.

International power sector market comes to realize that right size of conventional and non conventional resource for individual resource, distribution substation or micro grid could be the best possible solution of world mismatch of demand and supply of energy in economic way [9]. Although high penetration of DG set comes into the picture where power shedding is high and end users need continuous power for commercial, industrial operation, levelized cost of per unit generation is still high, it doesn't consider negative environmental impact [10]. Integration with Solar PV not only makes it viable, but also mitigates environmental issues in long terms and provides the cheap and clean energy due to declination of Solar PV system cost internationally [10]. 


\section{Electrification Rate-Rural \& Urban Population}

In many developing countries, the living condition of the majority of the poor has improved very little, especially in rural areas. The process of economic growth is traceable in large part of substitution of energy for wide range of activity, i.e. agriculture, industrial and domestic task. Energy alone is not sufficient to create the condition for economic growth, but it is certain necessary, and access to electricity is one of the clearest and undistorted indications of country's energy poverty status. The IEA estimated that in 20081.5 billion people or 22\% of world population had no access to electricity for whom 85\% lived in rural area. Since 2002 unelectrified population has declined worldwide by 161 million, despite the growth of world population more than 500 million. As per Alliance of Rural Electrification and IEA in 2008 electrification were at the rate of $78.2 \%$, where urban electrification share were $93.4 \%$ and rural electrification were $63.2 \%$, increasing slightly compare to the previous years (Figure 1).

According to Indian human development survey, 2005 RGGVY and other government policies, effort appeared to be reflected in rural electrification a $\mathrm{d} 72 \%$ of household have electricity, these facts and figures were $56 \%$ in 4 years back when study conducted by University of Maryland, IHDS, 2005. The central government has financed much of electricity development, but actual delivery of electricity to consumers is preliminary a state responsibility, therefore huge variation in planning, investment and execution of schemes for rural electrification. Himachal Pradesh, a hilly state with high penetration of hydro power plant, has virtually all households electrified including 98\% share of rural households. The highly developed state like Punjab, Jammu \& Kashmir and Haryana achieved more than 90\%, all states in southern regions has electrification more than $90 \%$ [11].

\section{Energy Demand \& Consumption Scenario-Rural and Urban Areas}

After the Industrial Revolution, not only the living pattern of people has been changed, but energy consumption pattern along with increasing population density in urban area. World demographic profile by World Bank shows that $50.50 \%$ of population lives in urban area remaining share by rural and remote area. The energy consumption growth, average per person, increased $10 \%$ while population increased by $27 \%$ between 1990 and 2008 according to IEA. Before the Industrial Revolution the productivity of a man dependent on his own labor and the amount of work he could be obtained from domestic animals. Most of developing countries are not heavily reach in commercial fuel such as oil, natural gas and coal. The non-commercial fuels, namely firewood, charcoal, animal dung cake and vegetable residues, are the primary energy resources used in rural households, agriculture, transportation, small-scale industries, services and construction. The proportion of consumption for domestic use in rural settlements varies from 30 to 70 percent of the total primary energy consumption. The consumption pattern shows that India's use of non conventional energy as proportion of total energy demand has been steady in time. Most of the non commercial fuel use is biomass which has steady declination from $65 \%$ to

\begin{tabular}{|c|c|c|c|c|c|c|c|c|c|c|c|c|c|c|c|c|c|c|c|c|}
\hline & \multicolumn{5}{|c|}{$\begin{array}{l}\text { Population without electricity } \\
\text { million }\end{array}$} & \multicolumn{5}{|c|}{ Electrification rate $\%$} & \multicolumn{5}{|c|}{ Urban electrification rate \% } & \multicolumn{5}{|c|}{ Rural Electrification rate \% } \\
\hline & 2002 & 2005 & 2008 & & & 2002 & 2005 & 2008 & & & 2002 & 2005 & 2008 & & & 2002 & 2005 & 2008 & & \\
\hline Africa & 535 & 554 & 589 & 19 & 35 & 35.5 & 37.8 & 40 & 2.3 & 2.2 & 62.4 & 67.9 & 66.8 & 5.5 & -1 & 19 & 19 & 22.7 & 0 & 3 \\
\hline North Africa & 9 & 7 & 2 & -2 & -5 & 93.6 & 95.5 & 98.9 & 1.9 & 3.4 & 98.8 & 98.7 & 99.6 & -0 & 0.9 & 87.9 & 91.8 & 98.2 & 3.9 & c \\
\hline Sub-Saharan Africa & 526 & 547 & 587 & 21 & 40 & 23.6 & 25.9 & 28.5 & 2.3 & 2.6 & 51.5 & 58.3 & 57.5 & 6.8 & -1 & 8.4 & 8 & 11.9 & -0 & 3.5 \\
\hline Developing Asia & 1019 & 930 & 809 & -89 & -121 & 68.7 & 72.8 & 77.2 & 4.1 & 4.4 & 86.7 & 86.4 & 93.5 & -0 & 7.1 & 59.3 & 65.1 & 67.2 & 5.8 & 2.1 \\
\hline China \& East Asia & 221 & 224 & 195 & 3 & -29 & 88.1 & 88.5 & 90.2 & 0.4 & 1.7 & 96 & 94.9 & 96.2 & -1 & 1.3 & 83.1 & 84 & 85.5 & 0.9 & 1.5 \\
\hline South Asia & 798 & 706 & 614 & -92 & -92 & 42.8 & 51.8 & 60.2 & 9 & 8.4 & 69.4 & 69.7 & 88.4 & 0.3 & 19 & 32.5 & 44.7 & 48.4 & 12 & 3.7 \\
\hline Latin America & 46 & 45 & 34 & -1 & -11 & 89.2 & 9 & 92.7 & 0.8 & 2.7 & 97.7 & 98 & 98.7 & 0.3 & 0.7 & 61.4 & 65.6 & 70.2 & 4.2 & 4 \\
\hline Middle East & 14 & 41 & 21 & 27 & -20 & 91.8 & 78.1 & 89.1 & -14 & 11 & 99.1 & 86.7 & 98.5 & -12 & 12 & 77.6 & 61.8 & 70.6 & -16 & 8.8 \\
\hline Developing countries & 1615 & 1569 & 1453 & -46 & -116 & 65.5 & 68 & 72 & 2.8 & 3.7 & 85.3 & 85.2 & 90 & -0 & 4.8 & 52.4 & 56.4 & 58.4 & 4 & 2 \\
\hline Transition \& OECD & 7 & 8 & 3 & 1 & -5 & 99.5 & 99.5 & 99.8 & 0 & 0.3 & 100 & 100 & 100 & 0 & 0 & 98.2 & 98.1 & 99.5 & -0 & 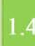 \\
\hline World & 1623 & 1577 & 1456 & -46 & -121 & 73.7 & 76 & 78.2 & 1.9 & 2.6 & 90.7 & 90.4 & 93.4 & -0 & 3 & 58.2 & 61.7 & 63.2 & 3.5 & \\
\hline
\end{tabular}

Figure 1. Electricity access to the world. http://www.ruralelec.org/9.0.html 
$27 \%$ in the last fifty years as per research report of deloitte, India [12] (Figure 2). This change has been primary brought about due to change in pattern of energy use, mostly in urban households. Both rural and urban households differed vastly in terms of their pattern of energy consumption from 1981 to 2011, 65\% urban population started using LPG up from 47\%, however, the change is not significant in rural household with only $11.4 \%$ of the household using LPG. In case of lighting, 92\% of urban households use electricity and 55\% of rural households use electricity for lightning [13].

Energy is essential ingredient in development bucket of country, but it also improves rural living standards, and provides development to each corner to country. Generally rural area lags behind the urban area in terms of energy use and access to modern energy. As of 2005 the percentage of household with electricity in urban India was $94 \%$ and in rural area was $57 \%$.

Inadequate supply is also the biggest issue in using modern energy. Although more than $94 \%$ of urban households in India have electrification, dwelling issue of unreliable supply of electricity is creating a big picture. Only $25 \%$ of urban households have 24 hours power supply, and as many as $18 \%$ of urban consumers have less than 12 hours power supply. Even this issue is very critical, only $6 \%$ of rural households have steady 24 hours supply, $26 \%$ have only 12 hours or few hours supply and 37\% do not have any electricity services according to Indian human development survey, 2005 [13] (Figure 3 and Figure 4). In the rural India, pattern of

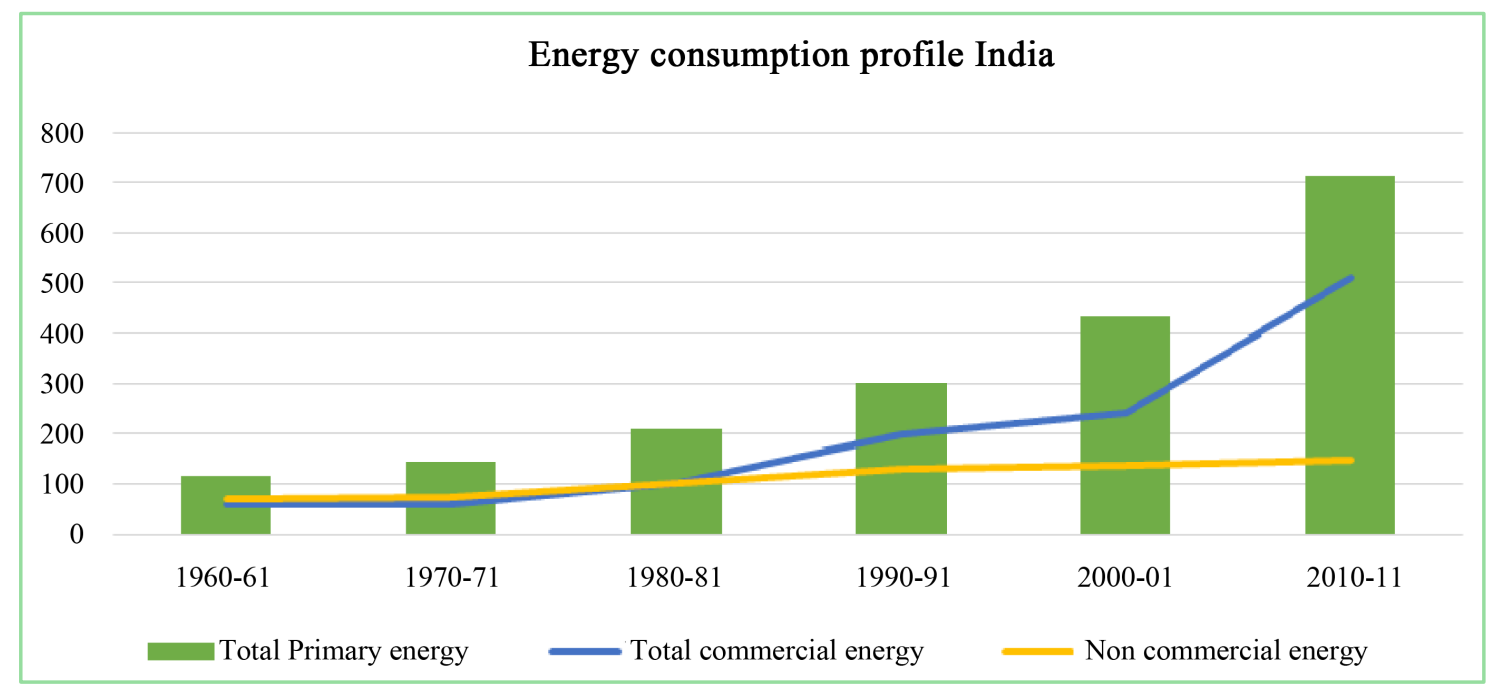

Figure 2. Energy consumption profile in India, Energy access to Poor, Delloite India.



Figure 3. Fuel use by urban and rural household. Source: IHDS, 2005. 


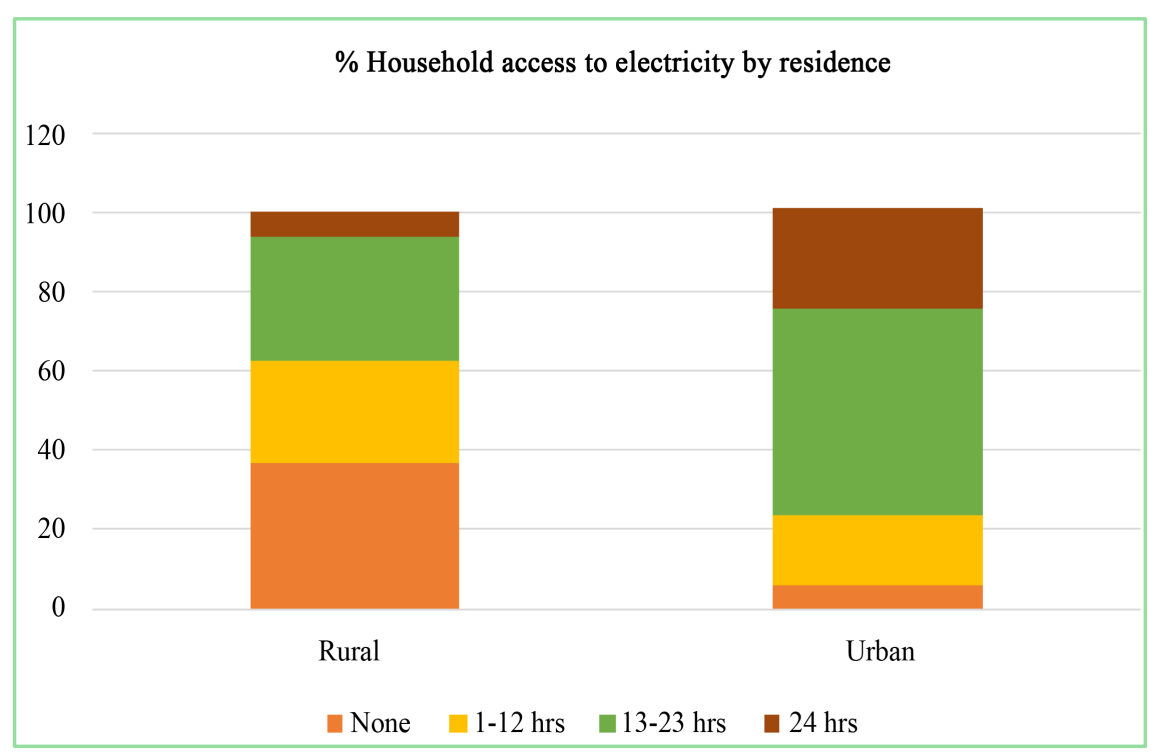

Figure 4. Household access to electricity by residence. Source: IHDS, 2005.

energy use typically involves high use of wood, biomass, kerosene, dung and straw where urban population uses only one third of population uses. In rural household, lighting is the major use of electricity, but in urban household, electricity use more than lighting including wide range of appliance i.e. TV, refrigerator, radio, iron, and AC. For rural households, fuel wood constitutes the highest share of total energy expenditure, at 40 percent. This expenditure may not represent what households actually paid. Since biomass is mostly collected without direct cost, the local market price has been used to impute the value of biomass use in rural areas. As per a survey conducted by IITD \& World Bank in 2008 (residential consumption of electricity in India, documentation of data and methodology), it estimated total power consumption of appliances, i.e. lighting, refrigeration, entertainment and heating \& cooling (Figure 5).

\section{Barriers \& Options to Energy Access in Rural \& Isolated Place}

The barriers or constrained to energy access to rural masses have their origin in financial, technical and geographical aspects. Sometimes inadequate focus of government and policy formulator, service provider's related issue are raised by the local bodies. Few issues of them are:

- Geographical isolated village and communities;

- Inadequate grid infrastructure;

- Insufficient focus on local resource;

- Lack of innovative \& adequate financing scheme;

- Lack of interest of private sector;

- Lack of deployment of mini grid, micro grids and decentralized solution;

- Lack of scalability of Solar PV technology, i.e. module, charging station, lantern and power packs;

- Limited market development and poor performance of energy programs;

- Willingness to pay;

- Program effectiveness.

All these issues need to be addressed by involving academicians, researchers, policy makers, regulators, financial institutions and private sectors. Although long distance and widely disturbed population have made it extremely difficult and expensive to provide access to grid electricity for rural isolated masses [14], there are two key options for addressing issue of energy access: 1) Grid Extension; 2) Decentralized Distribution Generation $(D D G)$. Many new business models are being tried by various governments in different countries, for practical decentralized solution is efficient and cost effective to energy access to remote places. Renewable sources are available, i.e. solar, wind, biomass and hydro, they can be incorporated with other power sources i.e. DG, Battery. 


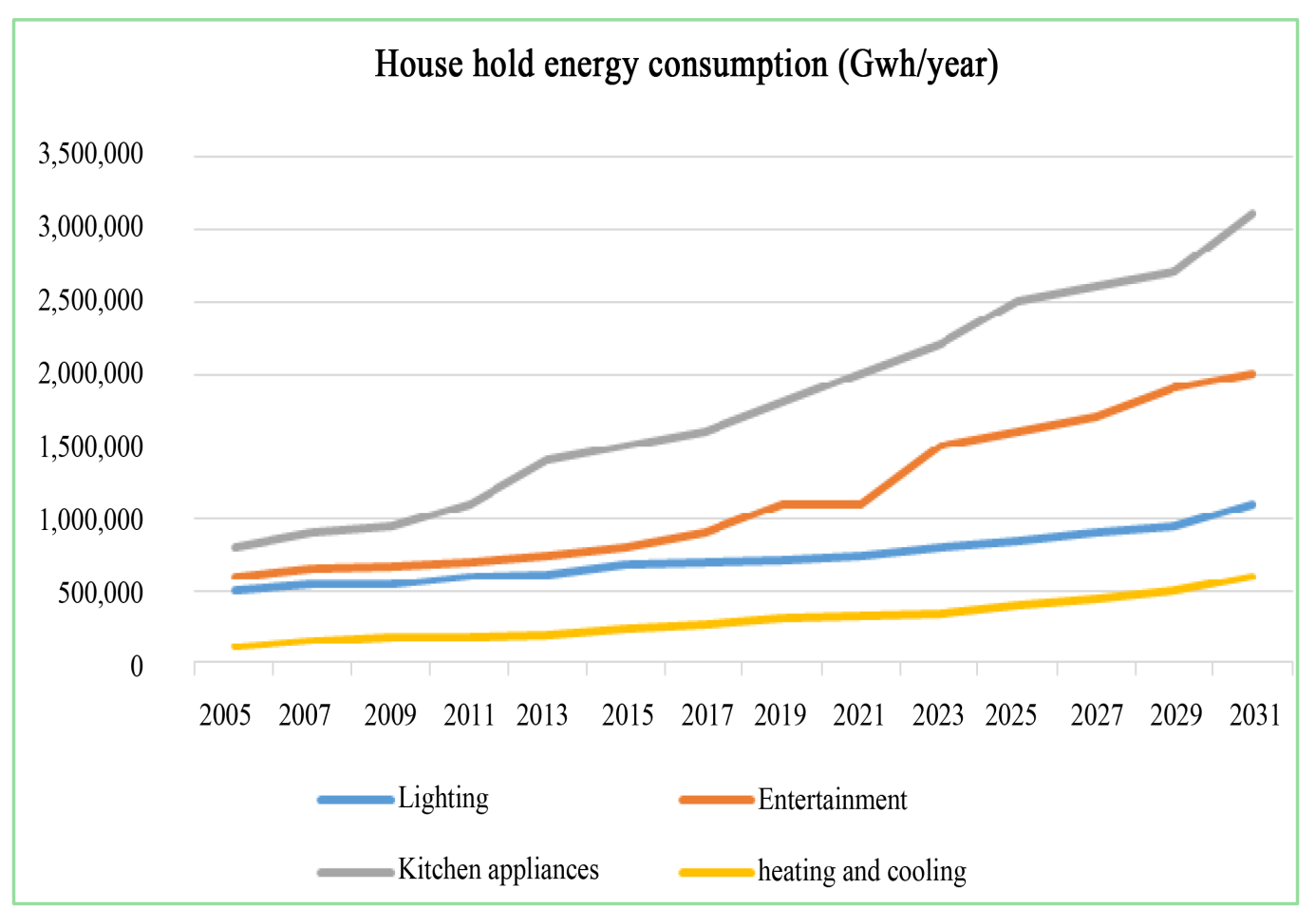

Figure 5. Household energy consumption. Source: world Bank, 2008.

Out of all renewable source of energy Solar PV works better in decentralized solution due to abundantly availability of sun shine in each corner compare to wind which is site specific.

\section{Decentralized Community Models-Justification}

Communities are comprised by cluster of no. of household with a premises based on their living patterns, place of residence and type of work performed. Uttarakhand is such a state in India where it shares 70\% population in hilly areas, consisting rural, semi urban, isolated area [15]. Taking the example of few districts out of thirteen which falling under the altitude level of 1000 - 2000 meters, Rudraprayag, Almora, Pauri, Chamoli, Uttarkashi, Pithoragarh, where most of the villagers, 5 - 6 no. of household groups form a village live in isolated location in hilly terrain. According to Uttarakhand health, family and welfare society reports that Uttarakhand is a predominately rural state, where $81 \%$ of village or cluster of village has population less than $500,17 \%$ of village covers a population of 500 - 2000 [16] and only 2.3\% share more than 2000 people in village. Such a small size of their demographic profile creates a difficulty in service delivery in villages [17]. The load profile has a significant effect on their energy use under the defined community model [18].

Community 1: It represents a small village consist small households with an annual average energy consumption of about 5 - $6 \mathrm{kWh} /$ day. It consists of $5-6$ no. of households. The residence connected to central via a micro grid that required wiring covered a length of 200 - 300 meters. The load profile of community has a small continuous load, i.e. mobile charger, CFL and has two day time peaks, and one between sunset and midnight (Figure 6 and Figure 7).

Community 2: It consumes an annual average of about $50 \mathrm{kWh} /$ day. It consists of 20 - 25 no. of small, medium and large households with a wide and high range of electrical appliances, i.e. mobile charge, TV, CFL, Incandescent bulb. The power distribution grid requires wiring length of approximately $3-4 \mathrm{~km}$. The load curve has two peaks in a 24 hour span i.e. during early morning, between evening and midnight. These peaks arise due to working activity and daily life style of household, size of household (Figure 8).

Community 3: Community 3 model consumes an annual average of $500 \mathrm{kWh} / \mathrm{day}$, and consists of small, medium and large household, school, small shop with floor mill. The distribution system requires about $20 \mathrm{~km}$ of wire. The load profile has one day time peak in the early morning and an evening peak between sundown and 


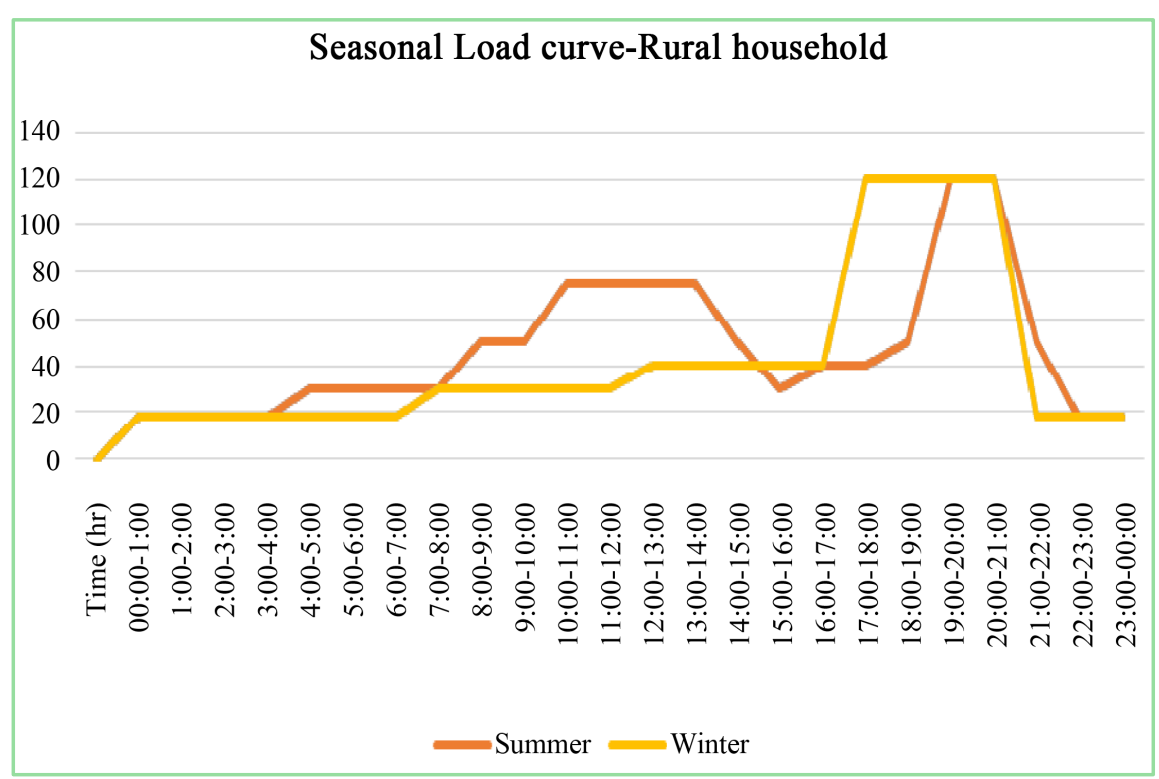

Figure 6. Daily energy consumption pattern rural household.

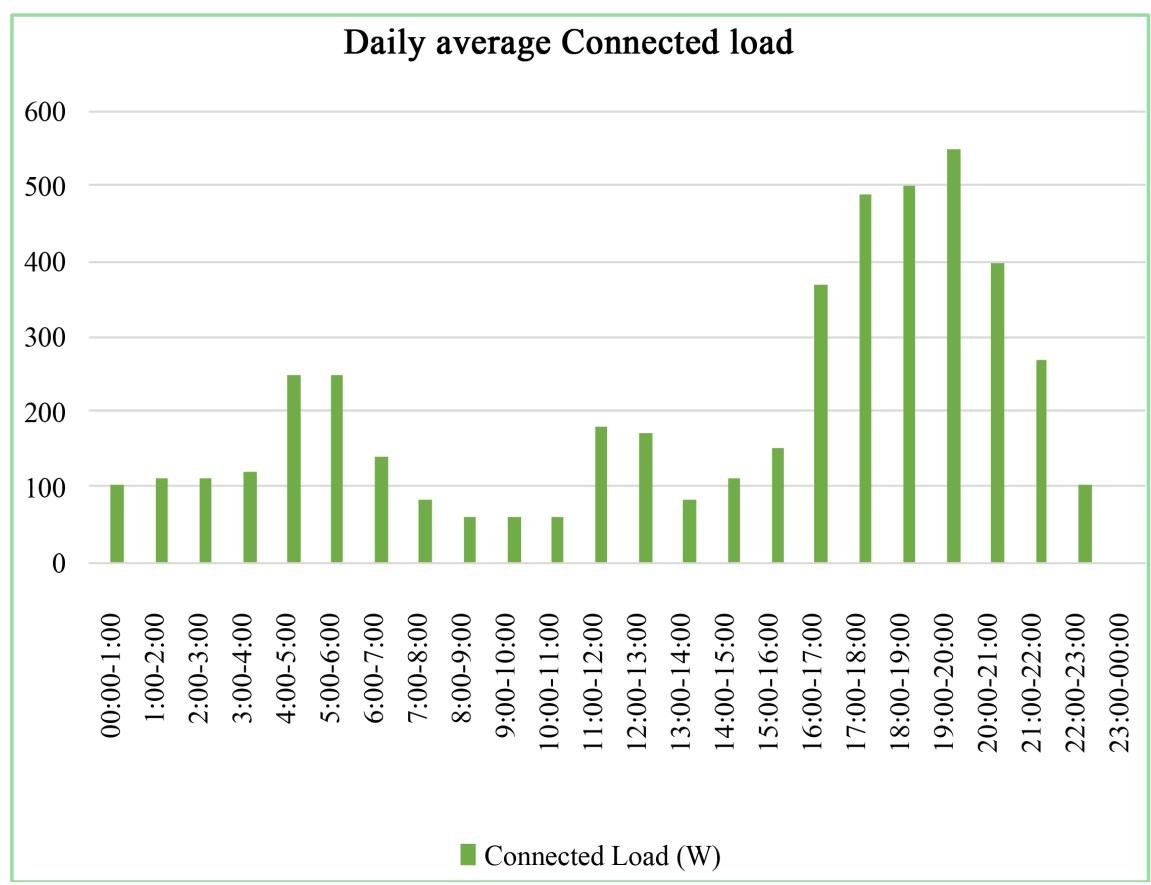

Figure 7. Daily average connected load, Community 1.

sunset. The day time load is even flatter because it consists varying loads of a range of household (Figure 9).

Standalone 1: The small standalone model represents a household or other single load with one or two small evening loads such as a television and efficient room lighting, and a small fan only during the day, average 1 $\mathrm{kWh} /$ day, peak $200 \mathrm{~W}$ (Figure 10).

Standalone 2: This application might represent an off-grid social gathering or household with predominantly evening loads. The load might include a small refrigerator, television, VCR, room and security lighting. The load is the highest between 16:00 and 24:00 when all appliances are operating. It is the lowest around midday when only the refrigerator is running, average $5 \mathrm{kWh} /$ day, peak $400 \mathrm{~W}$. Although social gathering places occasionally use (Figure 11). 


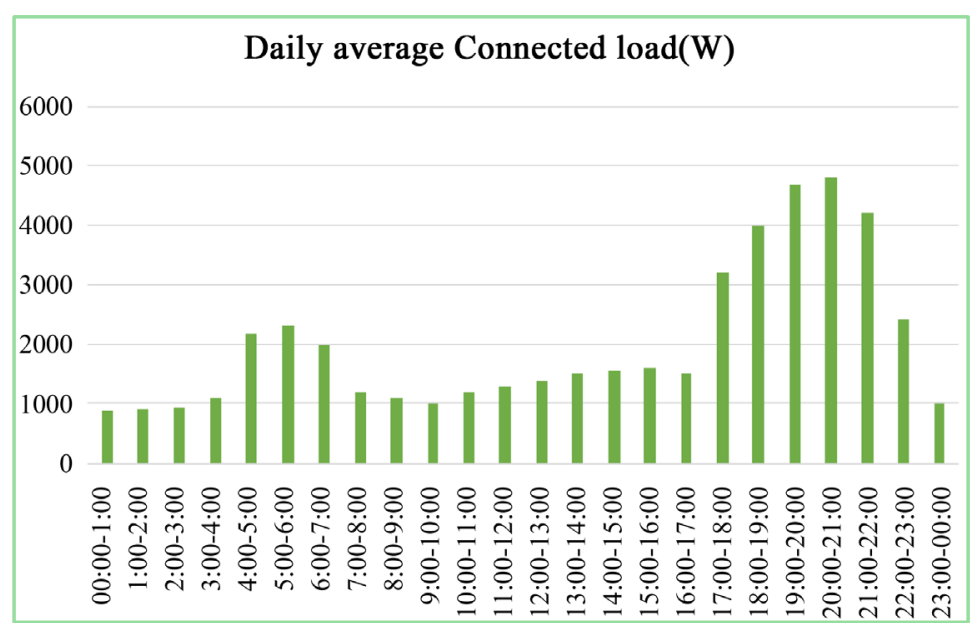

Figure 8. Time v/s daily avg. connected load, Community 2.

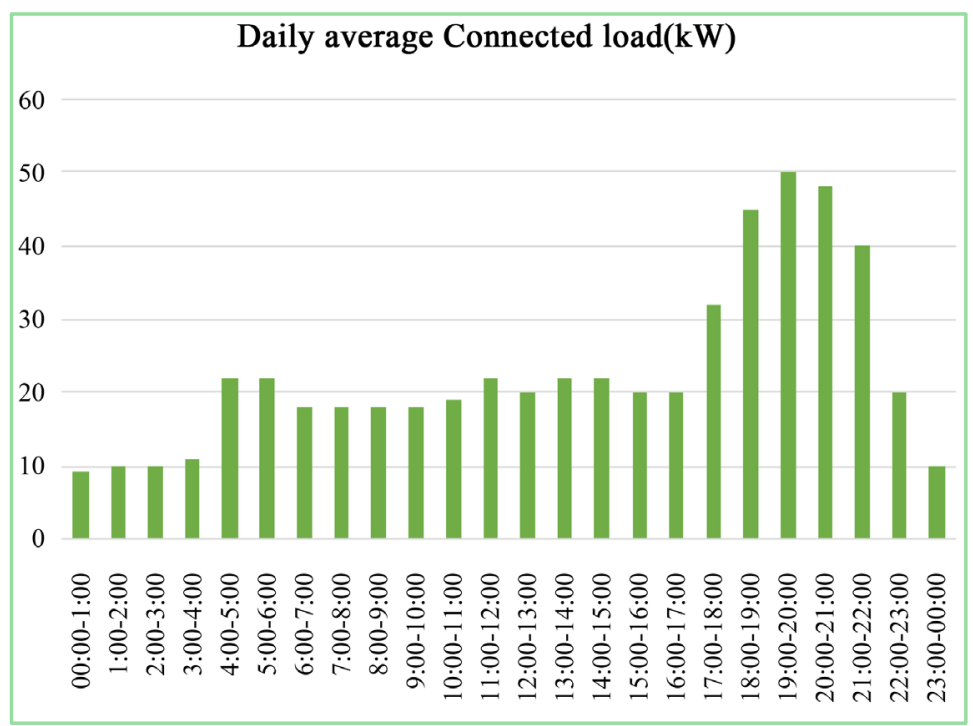

Figure 9. Time v/s daily avg. connect load, Community 3.

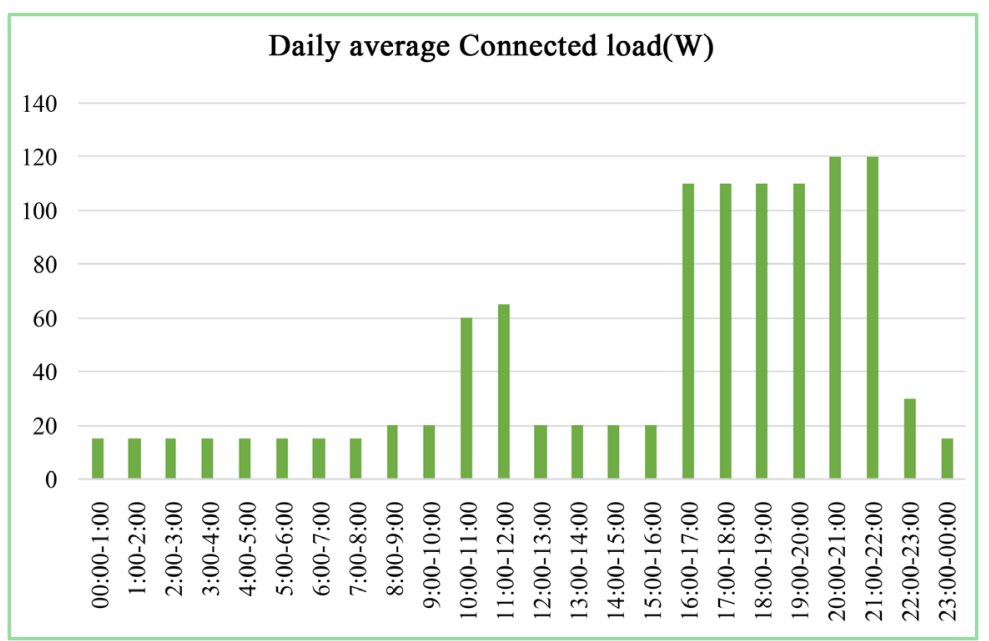

Figure 10. Daily average connected load of household. 


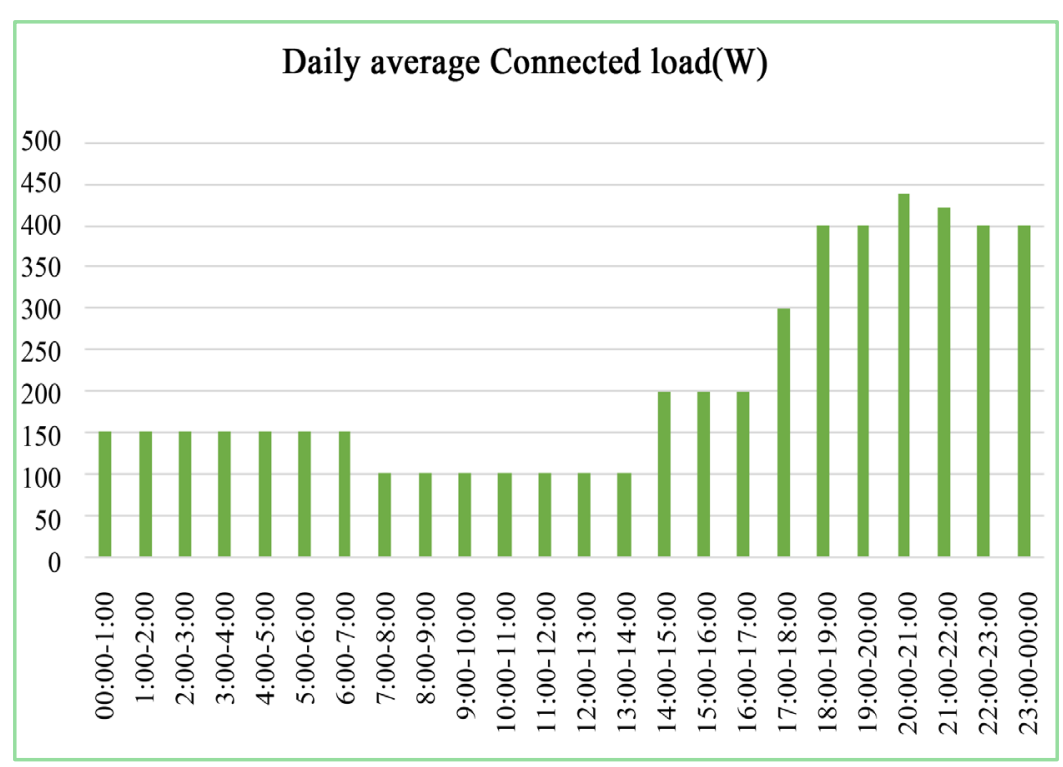

Figure 11. Daily average connected load.

\section{Hybrid Solar PV Model-Viable Solution}

Photovoltaic technology can significantly impact the socio-economic development of isolated rural world. The progressive electrification of area has not yet interconnected to the main electricity grid. Although with decreasing PV prices significantly, increasing cost of diesel fuel for operating DG and long term, maintenance free Tubular \& VRLA energy storage batteries have significantly attracted financial institute, project developer, NGOs and more over government to implement hybrid micro grid for energy access to rural and isolated place. The diesel generator set faces high cost of per unit generation, increases cost of fuel adding fuel transportation cost, adds high cost for single source of power generation comparing to Solar PV. The DG runs at low load factor at reduce efficiency, meanwhile Solar PV is an intermittent source of power generation required battery bank to stori the energy when sunshine is not available [19]. For above mentioned five community models, three types of hybrid technology are proposed for simulation:

1) Solar PV with Battery Bank;

2) Solar PV, DG set with battery Bank;

3) Solar PV with DG set.

\section{Simulation Outcomes}

Simulation has done on the basis of energy consumption of proposed community models through HOMER-a micro power simulation tool. Under this analysis, hybrid system capacity (in kW) based on the energy consumption has been selected. Following assumption has been taken for simulation:

- Annual interest rate $-12.50 \%$ (as per REC India);

- Inflation rate $-5.75 \%$ (as per mospi.nic.in);

- Solar PV system with battery bank (min 6 hrs backup) -190 Rs./Wp (as per MNRE guidelines);

- Diesel price per ltr. -55 Rs;

- Dollar exchange rate (1\$ = 60 INR) (as per economic times, average of past 6 months exchange rate).

Simulation report consists following results:

- System Architect;

- Levelized cost of Energy (LCOE);

- Capital Cost \& Total Cost (include O\&M, Replacement, Fuel cost, salvage value);

- Project Life Cycle: 25 years;

- Solar Radiation of Dehradun: $5.10 \mathrm{kWh} / \mathrm{m}^{2} / \mathrm{day}$ (as per HOMER);

- Annual Electrical Energy Demand \& Supply. 


\subsubsection{Community 1}

As per above mentioned decentralized community model, the energy consumption \& load curve has been given. Based on energy consumption, simulation results for hybrid systems are:

1) Solar PV and Battery Bank

System Architect: It consists $2 \mathrm{kWp}$ Solar PV plant, $1 \mathrm{KW}$ Converter (DC-AC) with 4 No. of each 12 V, 200 Ah battery to supply the required energy of $5 \mathrm{kWh} /$ day, peak load of $800 \mathrm{~W}$. Battery is sized with 2 days of battery back up.

Annual Energy Demand \& Supply: As per energy consumption pattern of Community 1, total annual energy consumption is approximately $2000 \mathrm{kWh}$. Solar PV is able to cater day time energy consumption and supply excess energy to charge the battery for using at night time.

Levelized Cost of Energy (LCOE): Based on the optimized simulation results through HOMER, the LCOE turns out to be $\$ 0.225 / \mathrm{kWh}$.

Capital Cost \& Total Cost (In \$): Based on the system architect, the capital cost has been taken as per benchmarking cost proposed for micro grids by the Ministry of New and Renewable Energy, Government of India. Total cost includes O\&M cost, component replacement cost and salvage value, and fuel cost through the life of the project.

Capital Cost: \$4075; Total Cost: \$ 6137.

2) Solar PV, DG with Battery Bank

System Architect: It consist $1.25 \mathrm{kWp}$ Solar PV plant, $1 \mathrm{KW}$ Converter (DC-AC ), 1 kVA DG with 4 No. of each $12 \mathrm{~V}, 150$ Ah battery to supply the required energy of $5 \mathrm{kWh} /$ day, peak load of $800 \mathrm{~W}$. Battery is sized with 2 days of battery back up. DG is used to cater the peak load in evening, considering 2 running hours per day.

Annual Energy Demand \& Supply: Total annual energy requirement will be met by generating 2398 units, 508 Units through Solar PV and DG respectively. Energy generated through PV will charge the battery for using the battery during non sunny hours in day and night.

Levelized Cost of Energy (LCOE): Based on the optimized simulation results through HOMER, the LCOE appears to be $\$ 0.331 / \mathrm{kWh}$.

Capital Cost \& Total Cost (In \$): Under this hybrid system, capital cost and total cost come out to be respectively $\$ 3081$ and $\$ 11,440$. Total cost is high due to replacement of DG and battery after completion of useful life. It also includes rising cost of fuel price.

3) Solar PV with DG

System Architect: It includes 1 KW Solar PV, 1 KW Converter with 1 KVA DG set to provide the energy requirement.

Annual Energy Demand \& Supply: Under this hybrid system DG will operate during the night time when peak load occurs and PV will supply energy at day time.

Levelized Cost of Energy (LCOE): Based on the simulation result, LCOE is $\$ 0.506 / \mathrm{kWh}$.

Capital Cost \& Total Cost (In \$): Total cost and capital cost carried out to be \$17,874 and \$1706 respectively.

Under this model, PV \& Battery is the cost effective solution considering life time of project is 25 years. Although initial capital cost is high due to high price of battery bank (Figure 12).

\subsubsection{Community 2}

1) Solar PV and Battery Bank

System Architect: It consists $15 \mathrm{kWp}$ Solar PV plant, $10 \mathrm{KW}$ Converter (DC-AC) with 24 No. of 2 V, 1500 Ah battery to supply the required energy of $50 \mathrm{kWh} /$ day, peak load of $7 \mathrm{KW}$. Battery is sized with 2 days of battery back up.

Annual Energy Demand \& Supply: As per energy consumption pattern of Community 2, total annual energy consumption is approximately 20,000 $\mathrm{kWh}$. Solar PV is able to cater day time energy consumption and supply excess energy to charge the battery for using night time.

Levelized Cost of Energy (LCOE): Based on the optimized simulation results through HOMER, the LCOE turns out to be $\$ 0.221 / \mathrm{kWh}$.

Capital Cost \& Total Cost (In \$): Based on the system architect, the capital cost has been taken as per benchmarking cost proposed for micro grids by the Ministry of New and Renewable Energy, Government of India. Total cost includes O\&M cost, component replacement cost and salvage value, fuel cost through the life of the 

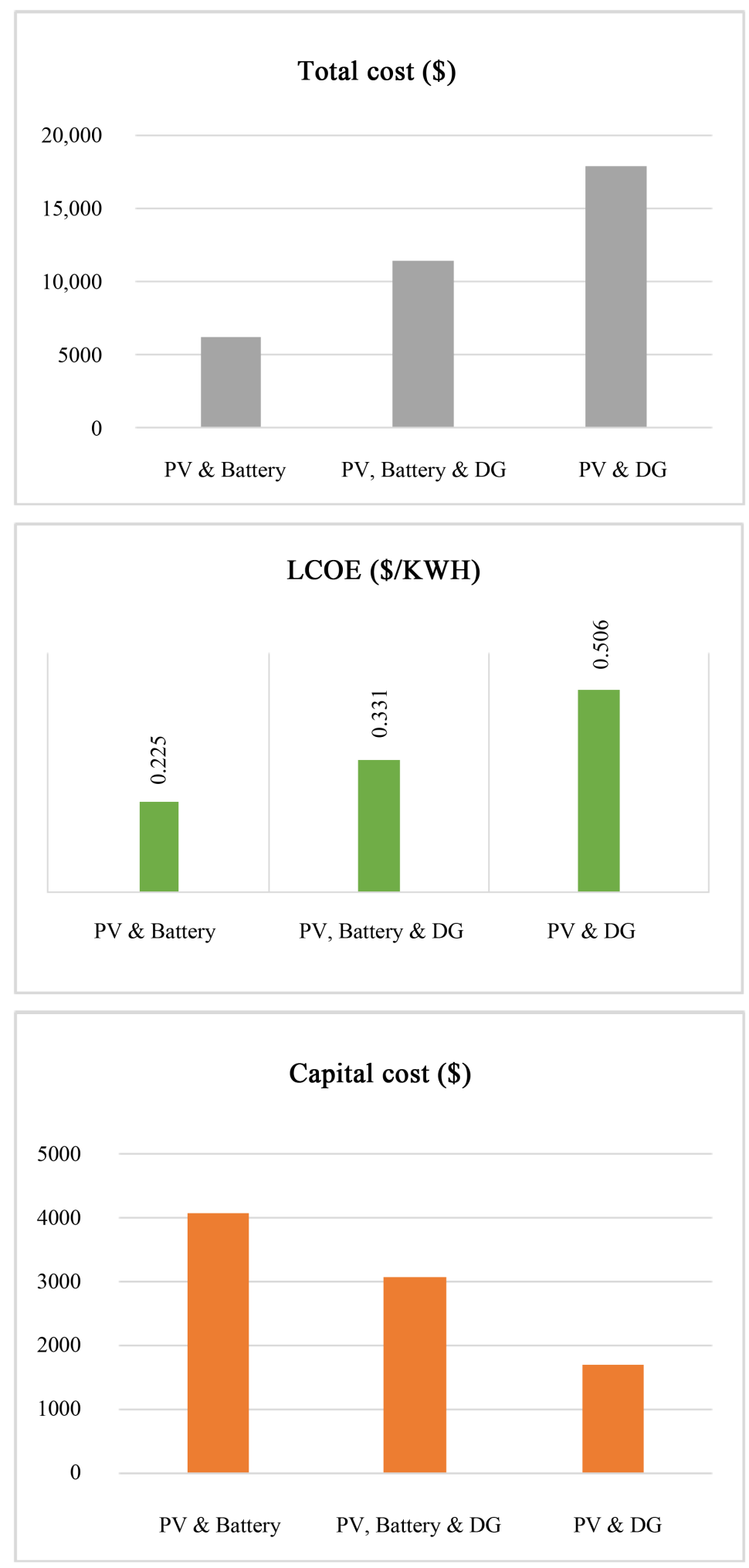

Figure 12. System wise comparison in Capital cost, LCOE and Total cost.

project.

Capital Cost: \$37,250; Total Cost: \$ 60,812. 
2) Solar PV, DG with Battery Bank

System Architect: It consists 15 kWp Solar PV plant, $10 \mathrm{KW}$ Converter (DC-AC), $10 \mathrm{kVA}$ DG with 24 No. of each $2 \mathrm{~V}, 1000 \mathrm{Ah}$ battery to supply the required energy of $50 \mathrm{kWh} /$ day, peak load of $7 \mathrm{KW}$. Battery is sized with 2 days of battery back up. DG is used to cater the peak load in evening, considering 2 running hours per day.

Annual Energy Demand \& Supply: Total annual energy requirement will be met by generating 18,250 units, 14,269 units through Solar PV and DG respectively. Energy generated through PV will charge the battery for using the battery during non sunny hours in day and night.

Levelized Cost of Energy (LCOE): Based on the optimized simulation results through HOMER, the LCOE appears to be $\$ 0.360 / \mathrm{kWh}$.

Capital Cost \& Total Cost (In \$): Under this hybrid system, capital cost and total cost come out to be respectively $\$ 35,750$ and $\$ 76,450$. Total cost is high due to replacement of DG and battery after completion of useful life. It also includes rising cost of fuel price.

3) Solar PV with DG

System Architect: It includes $10 \mathrm{KW}$ Solar PV, $10 \mathrm{KW}$ Converter with $10 \mathrm{KVA}$ DG set to provide the energy requirement.

Annual Energy Demand \& Supply: Under this hybrid system DG will operate during the night time when peak load occurs and PV will supply energy at day time.

Levelized Cost of Energy (LCOE): Based on the simulation result, LCOE is $\$ 0.438 / \mathrm{kWh}$.

Capital Cost \& Total Cost (In \$): Total cost and capital cost carried out to be $\$ 15,800$ and $\$ 90,633$ respectively.

In terms of capital cost PV \& DG is competing with system with Battery Bank and DG, but taking life cycle of project. Total cost of PV \& Battery model and LCOE of PV\& Battery BANK model is $\$ 0.221$, the lowest among all the proposed system (Figure 13).

\subsubsection{Community 3}

1) Solar PV and Battery Bank

System Architect: It consist $150 \mathrm{kWp}$ Solar PV plant, $60 \mathrm{KW}$ Converter (DC-AC) with 12 No. Battery bank 2 $\mathrm{V}, 2500$ Ah battery to supply the required energy of $500 \mathrm{kWh} /$ day, peak load of $60 \mathrm{KW}$. Battery is sized with 2 days of battery back up.

Annual Energy Demand \& Supply: As per energy consumption pattern of Community 2, total annual energy consumption is approximately $182,500 \mathrm{kWh}$. Solar PV is able to cater day time energy consumption and supply excess energy to charge the battery for using at night time.

Levelized Cost of Energy (LCOE): Based on the optimized simulation results through HOMER, the LCOE turns out to be $\$ 0.211 / \mathrm{kWh}$.

Capital Cost \& Total Cost (In \$): Based on the system architect, the capital cost has been taken as per benchmarking cost proposed for micro grids by the Ministry of New and Renewable Energy, Government of India. Total cost includes O\&M cost, component replacement cost and salvage value, and fuel cost through the life of the Project.

Capital Cost: \$ 349,500; Total Cost: \$577,280.

2) Solar PV, DG with Battery Bank

System Architect: It consists $150 \mathrm{kWp}$ Solar PV plant, $60 \mathrm{KW}$ Converter (DC-AC), $50 \mathrm{kVA}$ DG with 2 No of battery bank each $2 \mathrm{~V}, 2500$ Ah battery to supply the required energy of $500 \mathrm{kWh} /$ day, peak load of $50 \mathrm{KW}$. Battery is sized with 2 days of battery back up. DG is used to cater the peak load in the evening, considering 2 running hours per day.

Annual Energy Demand \& Supply: Total annual energy requirement will be met by generating 182,500 units, 191,876 units through Solar PV and DG respectively. Energy generated through PV will charge the battery for using the battery during non sunny hours in day and night.

Levelized Cost of Energy (LCOE): Based on the optimized simulation results through HOMER, the LCOE appears to be $\$ 0.318 / \mathrm{kWh}$.

Capital Cost \& Total Cost (In \$): Under this hybrid system, capital cost and total cost come out to be respectively $\$ 251,667$ and $\$ 906,981$. Total cost is high due to replacement of DG and battery after completion of useful life. It also includes rising cost of fuel price. 

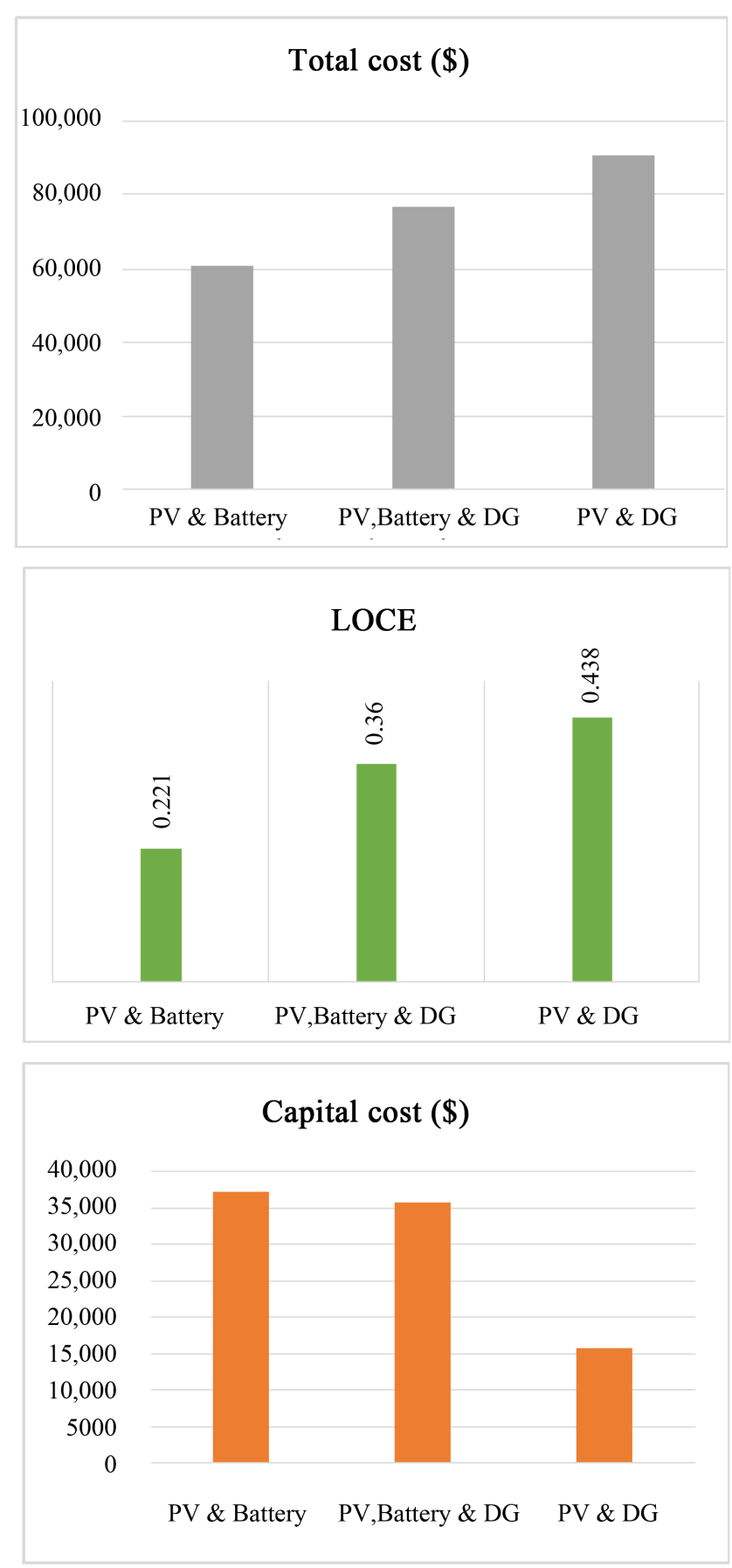

Figure 13. Cost comparison of Hybrid models for Community 2.

3) Solar PV with DG

System Architect: It includes 100 KW Solar PV, 60 KW Converter with 50 KVA DG set to provide the energy requirement.

Annual Energy Demand \& Supply: Under this hybrid system DG will operate during the night time when peak load occurs and PV will supply energy at day time.

Levelized Cost of Energy (LCOE): Based on the simulation result, LCOE is $\$ 0.426 / \mathrm{kWh}$.

Capital Cost \& Total Cost (In \$): Total cost and capital cost carried out to be $\$ 161,667$ and $\$ 1,183,699,633$ respectively 
Figure 14 shows that initial capital cost of PV \& Battery is high due to high cost of battery bank and PV module compare to the total life cycle cost, and LCOE comes out the lowest among all proposed hybrid models.

\subsubsection{Standalone 1}

1) Solar PV and Battery Bank

System Architect: It consists $0.50 \mathrm{kWp}$ Solar PV plant, $0.25 \mathrm{KW}$ Converter (DC-AC) with $12 \mathrm{~V}, 150$ Ah battery to supply the required energy of $1.0 \mathrm{kWh} /$ day, peak load of $200 \mathrm{~W}$. Battery is sized with 2 days of battery back up.

Annual Energy Demand \& Supply: As per energy consumption pattern of Community 2, total annual energy consumption is approximately $400 \mathrm{kWh}$. Solar PV is able to cater day time energy consumption and supply excess energy to charge the battery for using at night time.

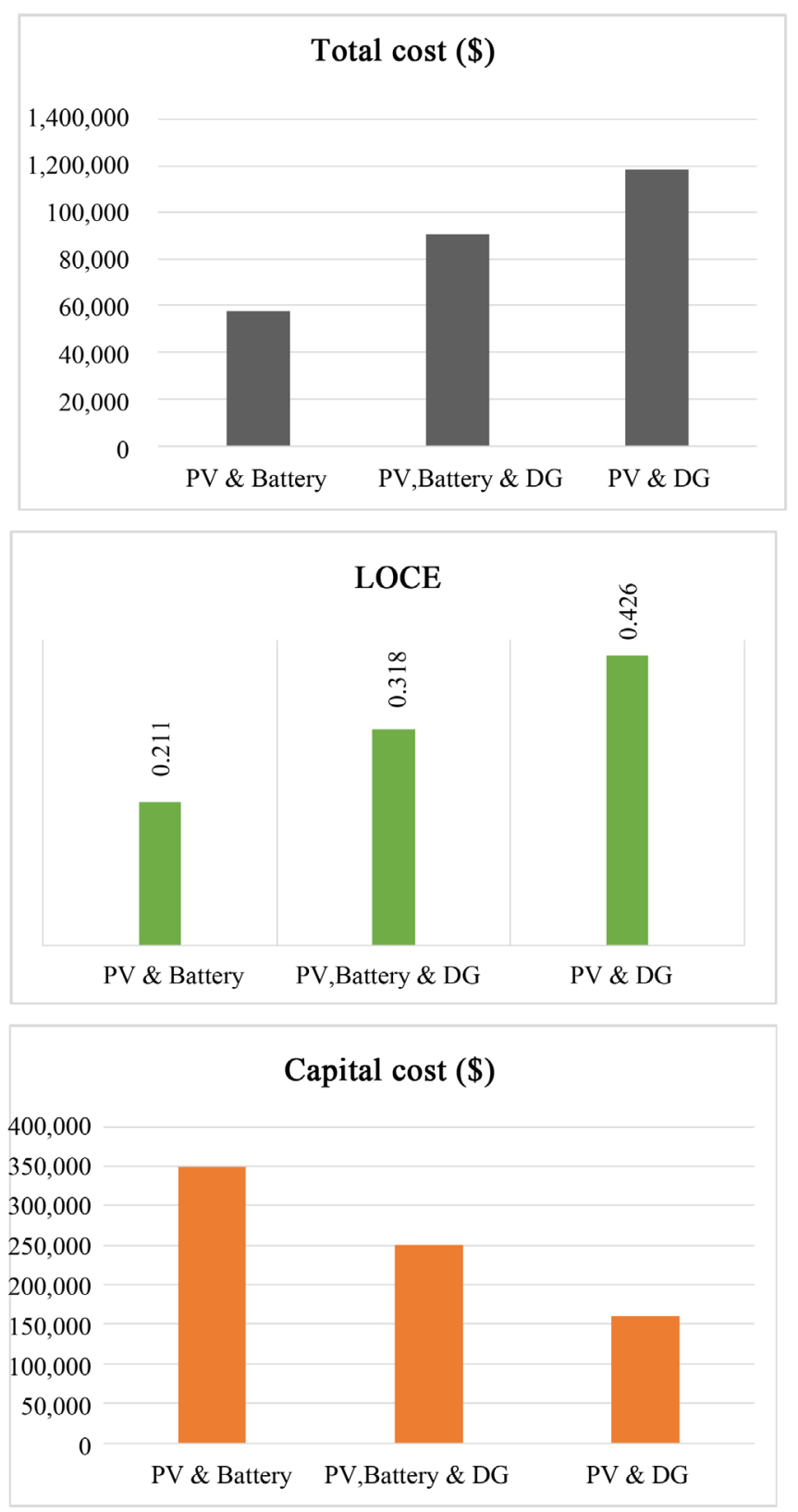

Figure 14. Comparison of Total cost, LCOE and capital cost under hybrid model in Community 3. 
Levelized Cost of Energy (LCOE): Based on the optimized simulation results through HOMER, the LCOE turns out to be $\$ 0.230 / \mathrm{kWh}$.

Capital Cost \& Total Cost (In \$): Based on the system architect, the capital cost has been taken as per benchmarking cost proposed for micro grids by the Ministry of New and Renewable Energy, Government of India. Total cost includes O\&M cost, component replacement cost and salvages value, and fuel cost through the life of the project.

Capital Cost: \$915, Total Cost: \$1967

2) Solar PV, DG with Battery Bank

System Architect: It consists $0.25 \mathrm{kWp}$ Solar PV plant, 0.250 KW Converter (DC-AC), 0.250 kVA DG with $12 \mathrm{~V}, 150$ Ah battery to supply the required energy of $1 \mathrm{kWh} /$ day, peak load of $200 \mathrm{~W}$. Battery is sized with 2 days of battery back up. DG is used to cater the peak load in evening, considering 2 running hours per day.

Annual Energy Demand \& Supply: Total annual energy requirement will be met by generating 479 units, 200 units through Solar PV and DG respectively. Energy generated through PV will charge the battery for using the battery during non sunny hours in day and night.

Levelized Cost of Energy (LCOE): Based on the optimized simulation results through HOMER, the LCOE appears to be $\$ 0.316 / \mathrm{kWh}$.

Capital Cost \& Total Cost (In \$): Under this hybrid system, capital cost and total cost come out to be respectively $\$ 702$ and $\$ 1852$. Total cost is high due to replacement of DG and battery after completion of useful life .It also includes rising cost of fuel price.

2) Solar PV with DG

System Architect: It includes $0.50 \mathrm{~kW}$ Solar PV, $0.50 \mathrm{KW}$ Converter with $0.50 \mathrm{KVA}$ DG set to provide the energy requirement.

Annual Energy Demand \& Supply: Under this hybrid system DG will operate during the night time when peak load occurs and PV will supply energy at day time.

Levelized Cost of Energy (LCOE): Based on the simulation result LCOE is $\$ 0.426 / \mathrm{kWh}$ (Figure 15).

Capital Cost \& Total Cost (In \$): Total cost and capital cost carried out to be \$450 and \$2623 respectively (Figure 15).

\subsubsection{Standalone 2}

1) Solar PV and Battery Bank

System Architect: It consists $1.50 \mathrm{kWp}$ Solar PV plant, $1 \mathrm{KW}$ Converter (DC-AC) with 2 No. each $12 \mathrm{~V}$, 1500 Ah battery to supply the required energy of $5 \mathrm{kWh} /$ day, peak load of $800 \mathrm{~W}$. Battery is sized with 2 days of battery back up.

Annual Energy Demand \& Supply: As per energy consumption pattern of Community 2, total annual energy consumption is approximately $1825 \mathrm{kWh}$. Solar PV is able to cater day time energy consumption and supply excess energy to charge the battery for using at night time.

Levelized Cost of Energy (LCOE): Based on the optimized simulation results through HOMER, the LCOE turns out to be $\$ 0.221 / \mathrm{kWh}$.

Capital Cost \& Total Cost (In \$): Based on the system architect, the capital cost has been taken as per benchmarking cost proposed for micro grids by the Ministry of New and Renewable Energy, Government of India. Total cost includes O\&M cost, component replacement cost and salvage value, and fuel cost through the life of the project.

Capital Cost: \$3206; Total Cost: \$7912.

2) Solar PV, DG with Battery Bank

System Architect: It consists $1.50 \mathrm{kWp}$ Solar PV plant, $1 \mathrm{KW}$ Converter (DC-AC), $1 \mathrm{kVA}$ DG with 2 No of battery bank each $12 \mathrm{~V}, 1500$ Ah battery to supply the required energy of $5 \mathrm{kWh} /$ day, peak load of $800 \mathrm{~W}$. Battery is sized with 2 days of battery back up. DG is used to cater the peak load in evening, considering 2 running hours per day.

Annual Energy Demand \& Supply: Total annual energy requirement will be met by generating 2857 units, 1300 units through Solar PV and DG respectively. Energy generated through PV will charge the battery for using the battery during non sunny hours in day and night.

Levelized Cost of Energy (LCOE): Based on the optimized simulation results through HOMER, the LCOE appears to be $\$ 0.321 \mathrm{kWh}$. 

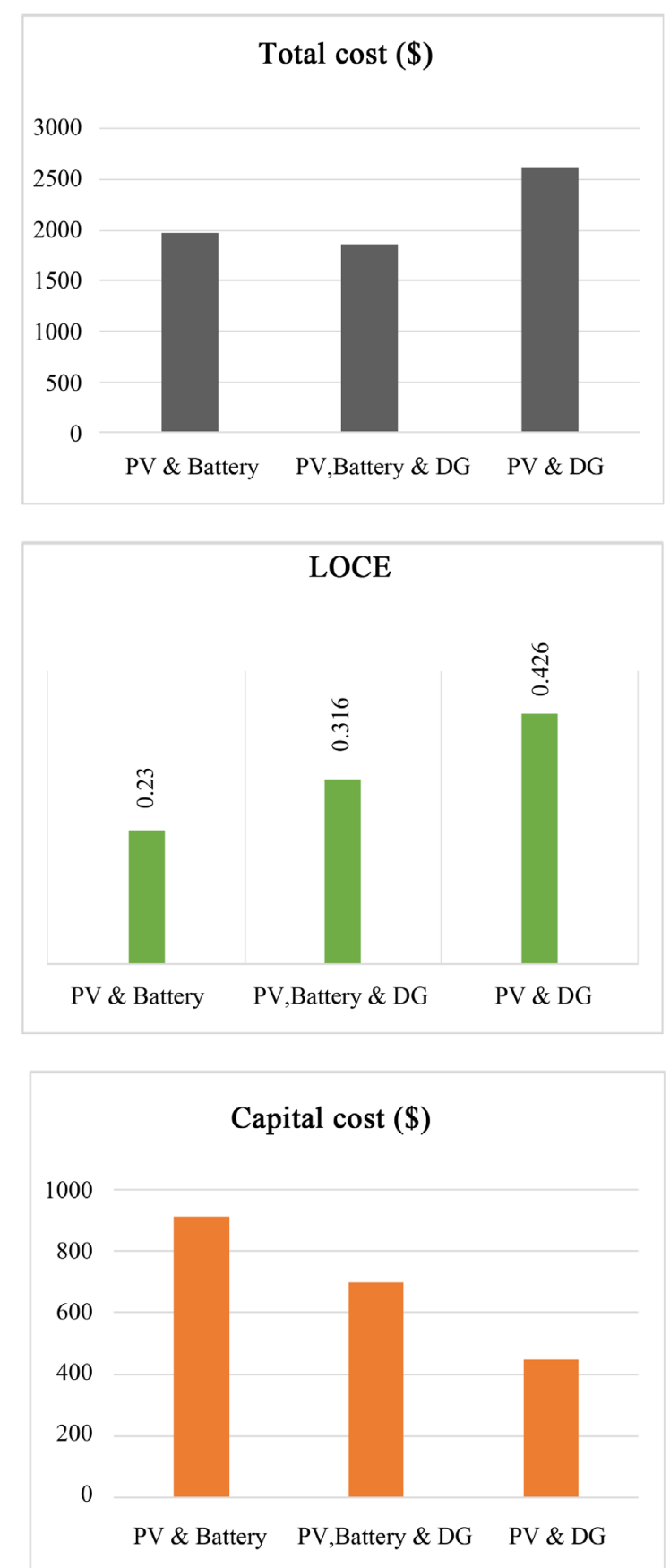

Figure 15. Cost comparison of proposed hybrid models for standalone1 community model.

Capital Cost \& Total Cost (In \$): Under this hybrid system, capital cost and total cost come out to be respectively $\$ 3367$ and $\$ 9152$. Total cost is high due to replacement of DG and battery after completion of useful life. It also includes rising cost of fuel price.

3) Solar PV with DG

System Architect: It includes 1 KW Solar PV, 1 KW Converter with 1 KVA DG set to provide the energy requirement.

Annual Energy Demand \& Supply: Under this hybrid system DG will operate during the night time when peak load occurs and PV will supply energy at day time. 
Levelized Cost of Energy (LCOE): Based on the simulation result, LCOE is $\$ 0.426 / \mathrm{kWh}$ (Figure 16).

Capital Cost \& Total Cost (In \$): Total cost and capital cost carried out to be $\$ 1956$ and $\$ 15,340$ respectively (Figure 16)

Under this simulation result, initial capital cost of PV \& Battery hybrid model is high compare to other proposed hybrid models. The LCOE turns out to be approximately \$0.221 in PV \& Battery hybrid model.
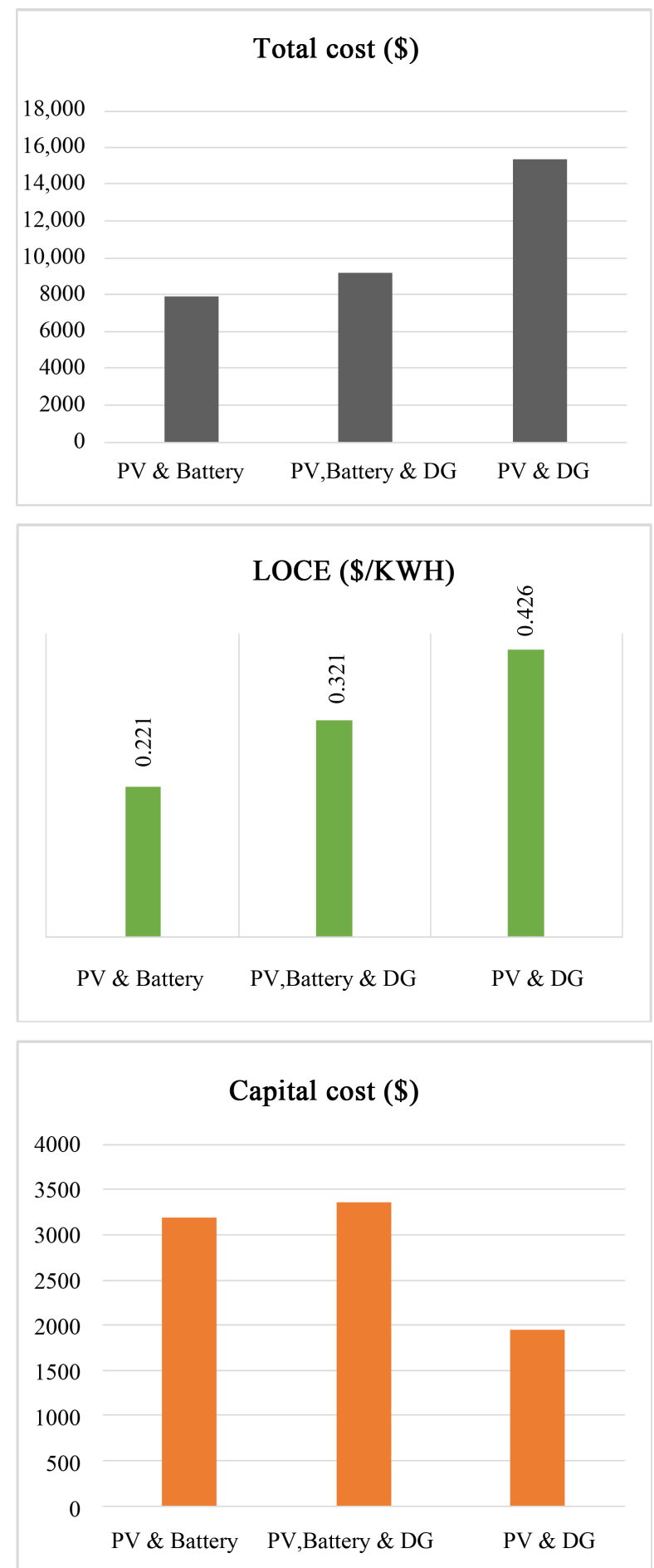

Figure 16. Cost comparison of Hybrid models in Standalone 2. 


\section{Results \& Discussion}

Simulation results show that initial investment is high in PV \& Battery hybrid model, after considering life cycle cost of model is turning out low compare to PV, Battery \& DG and PV, DG Model. The reason behind this is low maintenance cost of Solar PV module and no fuel requirement for running this model with battery bank, although replacement cost of battery bank increases the total life cycle cost of system. PV \& DG model is not economic viable due to increasing fuel cost and high O\&M cost including replacement of DG in every 7 - 8 Years. The levelized cost of energy is less in PV \& Battery model due to less life cycle cost of system compare to other hybrid models. Decentralized model for Dehradun, Uttarakhand would be economical viable for Governament, project developer and innovator to implement PV \& Battery hybrid model for energy access.

\section{Conclusions}

The study concludes that Decentralized Distributed Generation has economic viable solution to provide clean energy in isolated region of country. Decentralized distributed model for energy generation through Solar PV with option of Battery and DG will be more economic viable and low life cycle cost by engaging R\&D teams, Financial Institution to come up with innovative financing instrument for empowering rural sector.

Due to decrease in prices of PV module, incremental cost of DG fuel, and promises to provide accessibility of energy to all, the Solar PV with battery bank is economic solution.

\section{Acknowledgements}

I take this opportunity to express my deep sense of gratitude towards Co-author Mr. Saurabh Biswas, assistant professor, Department of Electrical, Power and Energy for his guidance and mentoring. Without his insight and guidance this minor project would never have achieved its full potential. I express my gratitude to Dr. Kamal Bansal, Dean College of Engineering Studies UPES, and Mr. N. B. Soni, Head of Department, Electrical Power and Energy, College of Engineering Studies, UPES, for his support of providing valuable suggestions and references to analyze the results of simulation. I also thank fully Mr. Anmol Singh Jaggi, Director Gensol Group and Ms. Shivya Singhal, Manger, Gensol Engineering Private Limited for continuous support to prepare the research paper.

\section{References}

[1] http://planningcommission.nic.in/plans/stateplan/present/Uttarakhand.pdf

[2] Holland, R., Perera, L., Sanchez, T. and Wilkinson, R. (2002) Decentralised Rural Electrification: The Critical Success Factors.

[3] Human Development Index —Sustaining Human Indexes. http://hdr.undp.org/en/statistics/hdi

[4] Strategic Environmental Assessment. http://www.worldenergy.org

[5] http://www.vernimmen.com/ftp/An introduction to distributed generation.pdf

[6] http://powermin.nic.in/

[7] http://uk.gov.in/home/

[8] Solar Energy Map of India, NREL \& MNRE.

[9] www.nrel.gov/international/geospatial_toolkits.htm

[10] Lovins, A. (2002) Small Is Profitable: The Hidden Economic Benefits of Making Electrical Resources the Right Size. Rocky Mountain Institute, Snowmass.

[11] DOE (2007) The Potential Benefits of Distributed Generation and Rate-Related Issues that May Impede Their Expansion. U.S. Department of Energy, Washington DC.

[12] Index Mundi (2012) World Demographics Profile 2012.

[13] http://www2.deloitte.com/in/en/pages/energy-and-resources/articles/energy-access-for-the-poor.html

[14] http://ihds.umd.edu/IHDS_files/05HDinIndia.pdf

[15] http://www.powermin.gov.in/

[16] Martin, J. (2009) Distributed vs. Centralized Electricity Generation: Are We Witnessing a Change of Paradigm? An Introduction to Distributed Generation. 
[17] http://www.ukhfws.org/details.php?pgID=mi_15

[18] NREL Geospatial Tool-HOMER.

[19] Rolland, S. and Glania, G. (2011) Hybrid Mini-Grids for Rural Electrification: Lessons Learned. Alliance for Rural Electrification, USAID, Brussels. 